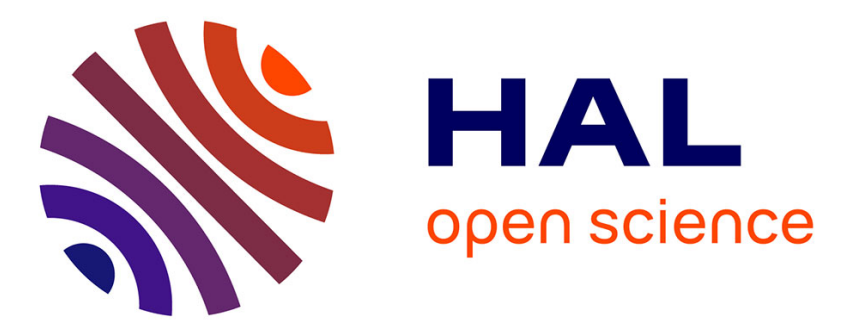

\title{
A 3D-CFD-heat-transfer-based model for the microbial inactivation of pasteurized food products
}

\author{
Clarissa Detomi de Albuquerque, Sébastien Curet, Lionel Boillereaux
}

\section{To cite this version:}

Clarissa Detomi de Albuquerque, Sébastien Curet, Lionel Boillereaux. A 3D-CFD-heat-transferbased model for the microbial inactivation of pasteurized food products. Innovative Food Science \& Emerging Technologies / Innovative Food Science and Emerging Technologies , 2019, 10.1016/j.ifset.2019.04.007 . hal-02332197

\section{HAL Id: hal-02332197 \\ https://hal.science/hal-02332197}

Submitted on 22 Oct 2021

HAL is a multi-disciplinary open access archive for the deposit and dissemination of scientific research documents, whether they are published or not. The documents may come from teaching and research institutions in France or abroad, or from public or private research centers.
L'archive ouverte pluridisciplinaire HAL, est destinée au dépôt et à la diffusion de documents scientifiques de niveau recherche, publiés ou non, émanant des établissements d'enseignement et de recherche français ou étrangers, des laboratoires publics ou privés.

\section{다)(1) $(5$}

Distributed under a Creative Commons Attribution - NonCommerciall 4.0 International 
1 A 3D-CFD-heat-transfer-based model for the microbial inactivation of pasteurized food 2 products

\section{Nomenclature}

$\begin{array}{ll}\mathrm{a}, \mathrm{b} & \text { dimensions of the elliptical sample }(\mathrm{mm}) \\ \mathrm{C}_{\mathrm{c}} & \text { critical component related to the physiological state of the cells (-) } \\ \mathrm{C}_{\mathrm{P}} & \text { apparent specific heat }\left(\mathrm{kJ} \mathrm{kg}^{-1} \mathrm{~K}^{-1}\right) \\ D_{\text {ref }} & \text { decimal reduction time }(\mathrm{s}) \\ \mathrm{g} & \text { gravitational constant }\left(\mathrm{m} / \mathrm{s}^{2}\right) \\ \mathrm{h}_{\text {air }} & \text { heat transfer coefficient of air }\left(\mathrm{W} \mathrm{m}^{-2} \mathrm{~K}^{-1}\right) \\ \mathrm{k}_{\max } & \text { specific inactivation rate }\left(\mathrm{s}^{-1}\right)\end{array}$




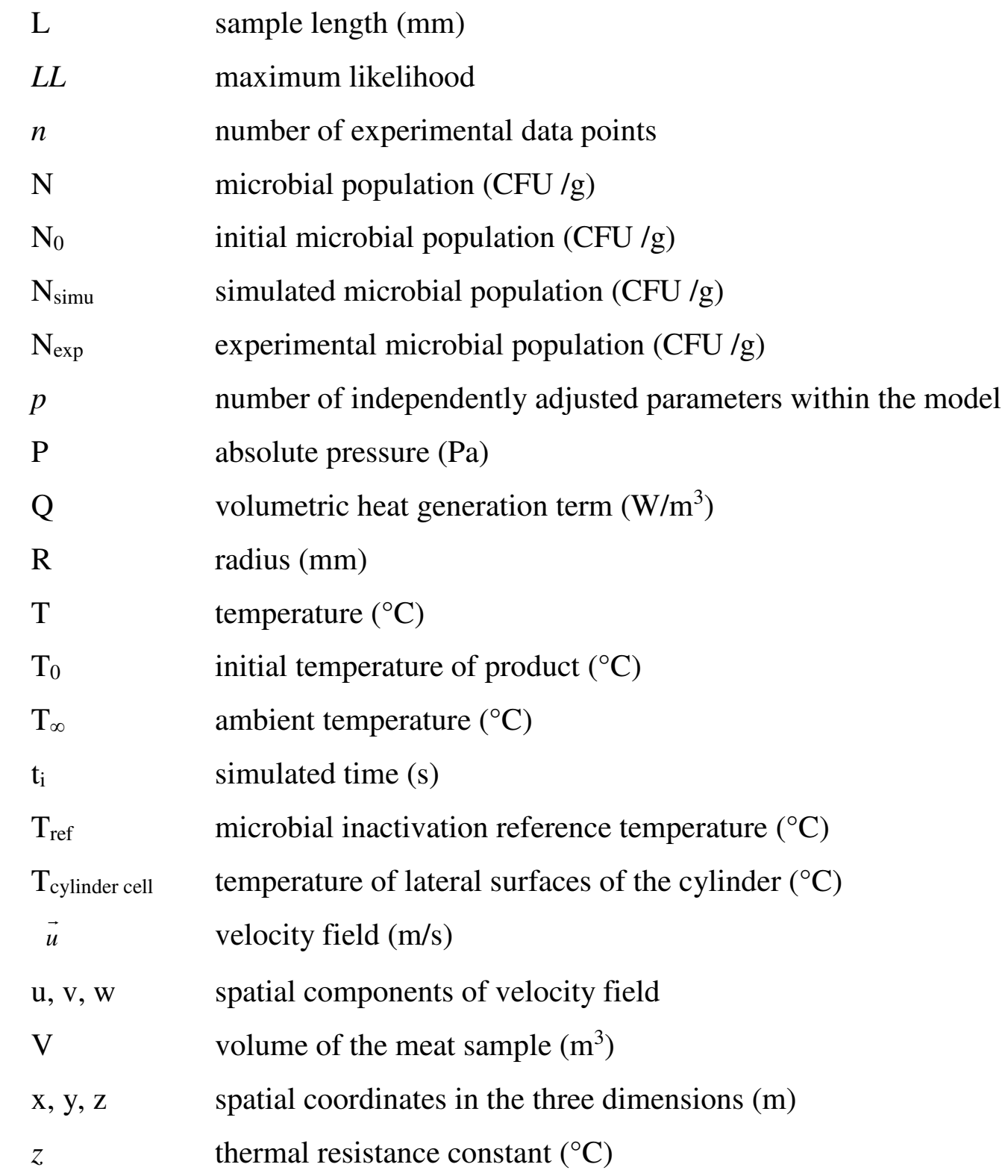

\section{Greek letters}

$\begin{array}{ll}\rho & \text { density }\left(\mathrm{kg} / \mathrm{m}^{3}\right) \\ \mu & \text { dynamic viscosity }(\mathrm{Pa} \mathrm{s}) \\ \sigma & \text { standard deviation of experimental data } \\ \lambda & \text { thermal conductivity }\left(\mathrm{W} \mathrm{m}^{-1} \mathrm{~K}^{-1}\right)\end{array}$

\section{Introduction}

Prediction of microbial inactivation during thermal treatment is crucial not only to ensure the safety of food products but also to avoid overtreatment (Boillereaux, Curet, Hamoud-Agha, \& Simonin, 2013). Although conventional processing technologies produce safe products, they can also lead to significant changes to the sensory and nutritional attributes of foods. In 
today's quality conscious world, much attention is given to producing foods that retain superior sensorial quality but must also remain safe (Bott, 2014; Stratakos \& Koidis, 2015). Consequently, the determination of the microbial destruction level that a thermal treatment can deliver to a product requires both understanding of: $(i)$ the heat transfer within the food product and (ii) the destruction kinetics of the microorganism of interest (Valdramidis et al., 2005). The necessity of such an approach is reinforced regarding the thermal heterogeneities that occur during a pasteurization process.

A reliable inactivation parameter estimation is essential for building predictive models (Chen, 2013) and is necessary to establish safe minimal cooking-cooling conditions (Marcotte, Chen, Grabowski, Ramaswamy, \& Piette, 2008). The determination of these parameters has been the subject of numerous studies, either under static (Ahmed, Conner, \& Huffman, 1995; Smith, Maurer, Orta-Ramirez, Ryser, \& Smith, 2001) or dynamic conditions (Garre et al., 2018; Hassani, Cebrián, Mañas, Condón, \& Pagán, 2006; Juneja \& Marks, 2003; Valdramidis, Geeraerd, Bernaerts, \& Van Impe, 2006; Valdramidis, Geeraerd, \& Impe, 2007). Different models have also been proposed to describe the microbial inactivation kinetics.

Numerous studies focusing on the estimation of microbial kinetic parameters are performed in isothermal and dynamic conditions, but under ideal laboratory conditions (capillary tubes, liquid inoculum and small sample mass). In real time industrial processing, food products are often submitted to time-varying temperatures. Moreover, due to several factors affecting heat transfer, i.e. geometry, thermophysical properties or external convection, significant thermal heterogeneities can occur. In the literature, the effect of capillary tube diameters on the inactivation parameters of $E$. Coli, in solid food, was investigated from a two-dimensional heat transfer approach (Chung, Wang, \& Tang, 2007).

A recent study by Garre et al., (2018) presented a mathematical model to describe the nonisothermal microbial inactivation process. The model was dedicated to Escherichia coli inactivation under linear heating rates of $1,5,15,35$ and $40{ }^{\circ} \mathrm{C} / \mathrm{min}$, from 35 to $70{ }^{\circ} \mathrm{C}$. The authors developed a mathematical model taking into account the thermotolerance of the microbial cells. The model was able to describe the experimental data using a unique set of model parameters.

Another investigation, Hamoud-Agha, Curet, Simonin, \& Boillereaux, (2013) proposed to estimate $D_{\text {ref }}$ and $z$-value of Bigelow's (1921) equation. These parameters were estimated for E. coli $\mathrm{K} 12$ inoculated into a model food under dynamic conditions (homogeneous 
temperature distribution due to a very small solid sample). These parameters were included in the Geeraerd et al., (2000) inactivation model coupled with a 3D-heat transfer model under microwaves to illustrate the resulting inactivation heterogeneity.

The literature is rich concerning CFD and heat transfer modelling dedicated to pasteurization of food products (Bhuvaneswari \& Anandharamakrishnan, 2014; Cordioli, Rinaldi, Copelli, Casoli, \& Barbanti, 2014; Denys, Pieters, \& Dewettinck, 2003; Dimou \& Yanniotis, 2011). However, except in Hamoud-Agha et al., (2013), it is rare to find these models coupled with microbial inactivation equations and even less with real products under external dynamic conditions. These elements reflect the originality of this work proposal. In this study, a 3DCFD and heat transfer approach is coupled with the Geeraerd et al. (2000) inactivation model. External temperature conditions (heating rates from 1 to $13{ }^{\circ} \mathrm{C} / \mathrm{min}$ ) are applied to Escherichia coli K12 inactivation in pre-packed ground beef. Model parameters are estimated from experimental data using the Levenberg-Marquardt algorithm (Marquardt, 1963).

\section{Materials and methods}

\subsection{Experimental section}

\subsubsection{Sample preparation}

Raw ground beef (Beef Steak $5 \%$ fat, Charal $^{\circledR}$, Cholet, France) was obtained from a local retail store. The proportion of lean meat and fat was determined on the basis of information on the package. Ground beef was provided in vacuum-packed portions of $100 \mathrm{~g}$. The samples were quickly frozen in a $-20{ }^{\circ} \mathrm{C}$ freezer (Servathin, Carrières-sous-Poissy, France) and stored in a freezing chamber at $-20 \pm 1^{\circ} \mathrm{C}$. Before each experiment, a bag of the sample was thawed for $18 \mathrm{~h}$ in a cooling chamber $\left(4^{\circ} \mathrm{C}\right)$.

\subsubsection{Preparation of bacteria inoculum}

The strain of Escherichia coli K12 (CIP 54.117, N 11.612) used in this study was provided by the Pasteur Institute, France, in the form of a freeze-dried sample. The strain was rehydrated in $0.2 \mathrm{~mL}$ and inoculated in $5 \mathrm{~mL}$ of Brain Heart Infusion (BHI) (Panreac Applichem - Darmstadt, Germany) at $37{ }^{\circ} \mathrm{C}$ for $18 \mathrm{~h}$ at $150 \mathrm{rpm}$ (Incubator Shaker Series Model Excella E24, New Jersey, USA). A pre-culture was prepared with $0.1 \mathrm{~mL}$ of the preceding suspension and inoculated in blood agar (Columbia $+5 \%$ Sheep blood - Bio-Rad - 
Marnes-la-Coquette, France) at $37^{\circ} \mathrm{C}$, for $18 \mathrm{~h}$. A clone of the pre-culture was then dissolved in $2 \mathrm{~mL}$ of sterile water $(0.85 \% \mathrm{NaCl}-$ Medium, BioMerieux $) .0 .1 \mathrm{~mL}$ of this solution was isolated in several Petri dishes of the blood agar with a sterile Pasteur pipette and incubated under the same conditions. The colonies of this second isolation were removed with a sterile swab and dissolved in $1 \mathrm{~mL}$ of the beef serum (Eurobio Serum Bovin, France) supplemented with $20 \%$ (v/v) glycerol and stored frozen at $-80{ }^{\circ} \mathrm{C}$ (Thermo Scientific TSE - USA).

To reactivate the strain, $0.1 \mathrm{~mL}$ of the stocked culture was inoculated into the blood agar (Columbia agar $+5 \%$ sheep blood -43041 , BioMérieux, France) and incubated at $37{ }^{\circ} \mathrm{C}$ for $18 \mathrm{~h}$. Fresh colonies were carefully removed with a sterile swab and dissolved in $5 \mathrm{~mL}$ of medium suspension (Api 20150, BioMérieux, France) until a cellular concentration of 0.5 McFarland was reached (Densitometer Densimat, BioMérieux, Italy). The optical density of $0.5 \mathrm{McF}$ arland standard is comparable to that of a bacterial suspension concentration of approximately $1.5 \times 10^{8} \mathrm{CFU} / \mathrm{mL}$ (CLSI, 2012).

\subsubsection{Inoculation of ground beef}

Raw ground beef samples ( $36 \mathrm{~g}$ ) were removed aseptically from their refrigerated packaging $\left(7^{\circ} \mathrm{C}\right)$ and transferred into sterile polypropylene sampling pouches with $4 \mathrm{~g}$ of bacterial suspension. Ground beef was mixed manually to evenly distribute the inoculum throughout the sample, producing an initial cell concentration of approximately $10^{7} \mathrm{CFU} / \mathrm{g}$. For heat treatment, $3 \mathrm{~g}$ of inoculated ground beef samples were aseptically placed in packaging of $11.6 \mathrm{~mm}$ wide x $60 \mathrm{~mm}$ long.

\subsubsection{Heat treatment for microbial inactivation}

As illustrated in Figure 1, each sample was inserted into the cylindrical vessel and submitted to a linear heating ramp in a programmable Peltier-based effect water bath (Hart Scientific AOIP, FC 9105, USA). After the heating treatment, the sample was quickly cooled to $20{ }^{\circ} \mathrm{C}$ by ice immersion. The temperature was measured with a thermocouple (type-K) positioned near the bottom of the sample. The data were collected by a data logger (AOIP Datalog, 91133 Ris Orangis, France) with output recordings every 1 second. To obtain the inactivation kinetics curves, eight final temperatures $\left(50,52,54,56,58,60,62\right.$ and $\left.64{ }^{\circ} \mathrm{C}\right)$ were considered. Six different heating rates $\left(1,3,5,7,10\right.$ and $\left.13^{\circ} \mathrm{C} / \mathrm{min}\right)$ were applied. Triplicates were carried out for each experiment. 


\subsubsection{Microbial enumeration and expression of results}

The method of analysis was according to ISO 16649-1 (2001). This standard procedure specifies a horizontal method for the enumeration of $\beta$-glucuronidase-positive Escherichia coli in products intended for human consumption. It is based on a colony-count technique at $44{ }^{\circ} \mathrm{C}$ in a solid medium containing a chromogenic ingredient for detection of the $\beta$ glucuronidase enzyme (ISO 16649-1, 2001).

Untreated inoculated ground beef and treated ground beef were aseptically removed from the packaging and transferred to a sterile filtered stomacher bag $(400 \mathrm{~mL}$, BagPage, St. Nom, France). The samples were diluted with 1:9 (w/w) of buffered peptone water (BK131HA, Biokar Diagnostics, France) and stomached for $2 \mathrm{~min}$ at $230 \mathrm{rpm}$ (Stomacher Lab Blender InterscienceBagMixer® - 400, Grosseron, St. Herblain, France). Decimal serial dilutions were performed in buffered peptone water. $1 \mathrm{~mL}$ of the initial suspension or decimal dilution was inoculated onto duplicate plates of tryptone-bile-glucuronic (TBX) medium (BK146HA, Biokar Diagnostics, France) and incubated between $18 \mathrm{~h}$ to $24 \mathrm{~h}$ at $44{ }^{\circ} \mathrm{C}$. The presence of blue colonies is considered to be $\beta$-glucuronidase-positive Escherichia coli.

Each dish containing less than 150 typical CFU was numbered and the result was calculated as the arithmetic mean from two parallel plates. The results expressed to the base 10 logarithm of the microbial population for each temperature measurement were collected. The detection limit was fixed to $1 \mathrm{CFU} / \mathrm{g}$ of the ground beef.

\subsection{Model design section}

\subsubsection{Heat transfer and computational fluid dynamics (CFD)}

The experimental methodology described in section 2.1.4 was considered in a CFD-heat transfer model, with the following assumptions:

- Assumption 1: Water in the cylindrical vessel and the packaged sample were at the same initial homogeneous temperature $\left(7^{\circ} \mathrm{C}\right)$.

- Assumption 2: The ground beef sample was considered as being homogeneous and isotropic.

- Assumption 3: Specific heat, density and thermal conductivity of the ground beef were considered as being constant within the temperature range (Pan \& Paul Singh, 2001; Tsai, Unklesbay, Unklesbay, \& Clarke, 1998). 
- Assumption 4: The geometry of the packaged sample was an ellipsoid-cylinder and the cross-section was considered homogeneous along the z-coordinate.

- Assumption 5: Axial symmetry was supposed for both thermal problems and fluid mechanics, limiting the size to one quarter of the experimental apparatus.

- Assumption 6: The mass transfer and the shrinkage of the sample were assumed to be negligible (in-package thermal treatment).

- Assumption 7: The package thickness was sufficiently thin to neglect its impact on the heat transfer (low thermal resistance).

The model is aimed at predicting the temperature profile when a heating rate is applied to the wall of the water bath heating cell. The model consists of two main computational domains: the first relates to liquid water which partially fills the cylindrical cell, the second is the ground beef sample located at the centre of the cell. As illustrated in Figure 2, the sample was immersed in water and its upper surface was exposed to air surrounding the medium (natural convection). The lateral surfaces of the cylinder are modelled with a first type boundary condition $\left(\mathrm{T}=\mathrm{T}_{\text {cylinder cell }}\right)$.

\subsubsection{Heat transfer modelling}

Heat transfer is based on the general heat equation, which depends on thermophysical properties. For the ground beef sample, the heat equation is reduced to:

$$
\rho_{(\text {sample })} C_{p(\text { sample })} \frac{\partial T}{\partial t}=\operatorname{div}\left(\lambda_{(\text {sample })} \nabla T\right)
$$

For liquid water, a convective term is added to take into account the variation of the thermophysical properties of water as a function of temperature:

$\rho_{\text {(water) }} C_{p(\text { water })} \frac{\partial T}{\partial t}+\rho_{(\text {water })} C_{p(\text { water })} \vec{u} \nabla T=\operatorname{div}\left(\lambda_{\text {(water })} \nabla T\right)$

Where $\vec{u}$ is the velocity field at any point of the 3D sample domain $(u, v, w$ components).

The initial and boundary conditions are defined with the following mathematical expressions:

$$
T=T_{0}, \quad t=0, \quad \forall(x, y, z), \quad T_{0}=7^{\circ} \mathrm{C}
$$

$$
\left.\lambda_{\text {(sample/water) }} \frac{\partial T}{\partial z}\right|_{z=L}=h_{\text {air }}\left(T-T_{\infty}\right), \quad \forall(x, y,), \forall t>0, \quad T_{\infty}=20^{\circ} \mathrm{C}
$$


The boundary condition expressed by equation 4 is applied to the upper surface of water and sample.

$$
T_{\text {cylindrical cell }}=T_{0}+\frac{d T}{d t} t\left\{\begin{array}{l}
\text { for }(x, y) \in[0 ; R] \text { and } Z=0, \quad \forall t>0 \\
\text { for } x, y=R, \quad \forall t>0, \text { for } Z \in[0, L]
\end{array}\right.
$$

Figure 2 displays the coordinate system used to describe these mathematical expressions.

The convective heat transfer coefficient is due to natural convection between the surrounding air medium and the upper surface of the product. Free convection occurs only at the upper surface of both the water and the sample (Figure 2). An empirical correlation was conducted to compute the heat transfer coefficient on the upper cooled side of the cylinder. The air heat transfer coefficient $\left(h_{\text {air }}\right)$ at the surface of the vertical cylinder with its axis running vertically is the same as that from a vertical plate, so long as the thermal boundary layer is thin (Churchill \& Chu, 1975).

\subsubsection{Fluid flow modelling}

The fluid flow is due to natural convection occurring within the liquid water. This convective flow is modelled from the Navier Stokes equations (Newtonian fluid with incompressible flow). Both the continuity and momentum equations are described as follows:

$$
\begin{cases}\frac{\partial u}{\partial x}+\frac{\partial v}{\partial y}+\frac{\partial w}{\partial z}=0 & \text { (continuity) } \\ \rho_{\text {water }} \frac{d \vec{u}}{d t}=\rho_{\text {water }} g-\nabla P+\mu_{\text {water }} \Delta \vec{u} & \text { (momentum) }\end{cases}
$$

with

The associated initial and boundary conditions are given as:

$$
\begin{gathered}
P=P_{a t m}+\rho_{\text {water }} g z \quad \text { at } t=0, \forall x, y, \quad \text { for } z \in[0 ; L] \\
\vec{u}=0 \text { at } R=x, y, \quad \forall t>0, \quad \text { for } z \in[0 ; L]
\end{gathered}
$$


For validation purposes, coupled heat transfer and fluid flow were solved for a heating rate of $10{ }^{\circ} \mathrm{C} / \mathrm{min}$ to compare the simulation to experimental results in the same conditions.

\subsubsection{Thermophysical properties}

Thermophysical properties of the sample used for modelling purposes are listed in Table 1. The apparent specific heat $\left(C_{p}\right)$ of ground beef (5\% fat) was determined using a differential scanning calorimetry ( $\mu$ DSC VII Evo - Setaram Instrumentations, France) at a constant pressure. Samples $(\sim 500 \mathrm{mg})$ were weighed in aluminium cells and sealed. A hermetically sealed empty cell was used as a reference. The samples were equilibrated at $20{ }^{\circ} \mathrm{C}$ and then heated to $65{ }^{\circ} \mathrm{C}$, at a heating rate of $1{ }^{\circ} \mathrm{C} / \mathrm{min}$. The measurements were made in triplicate and the average values were determined.

The density and the thermal conductivity of sample were taken from Pan \& Paul Singh (2001). The authors reported densities of $1006-1033 \mathrm{~kg} / \mathrm{m}^{3}$ and thermal conductivities of $0.35-0.41 \mathrm{~W} \mathrm{~m}^{-1}{ }^{\circ} \mathrm{C}^{-1}$ of ground beef (4.8\% fat). These values do not change significantly as a function of temperature range (between 5 and $75{ }^{\circ} \mathrm{C}$ ).

Thermophysical properties of water were considered as temperature dependent (Green \& Perry, 2007). These properties were directly implemented in the model using polynomial interpolation functions (Table 2).

\subsubsection{Computational details for CFD simulations}

Based on the finite element method, the model solved the partial differential equations numerically, with the computational code COMSOL $^{\circledR}$ Multiphysics 5.3a. In this study, the geometry consisted of irregular shapes (ellipsoid-cylinder with axial symmetry) justifying the use of the finite element method to simulate the coupled CFD-heat transfer phenomenon.

As shown in Figure 3, the generated mesh was designed for a 3D configuration, to ensure good accuracy for the numerical resolution (522 830 tetrahedral elements with appropriate boundary layers at the near-cell wall zone). Additional mesh sensitivity studies were performed to obtain accurate number of mesh elements in relation to the computational cost. The mesh independency to the numerical results was also verified. First, the fluid flow was solved as a stationary study in order to initialize the velocity field for a better consistent initial value. 
Due to the temperature-dependent thermophysical properties of water, the coupled equations (Eq. 6 and 7) within fluid and heat transfer within the meat sample (Eq. 1) and water (Eq. 2) were solved as a time-dependent study with a direct solver (strong coupling). To ensure a good consistent initial value, the initial time step for the resolution was fixed at $10^{-7} \mathrm{~s}$. Based on these computational details, the computational time did not exceed 4 hours 9 minutes and 12 seconds on a Dell ${ }^{\circledR}$ Precision TM Workstation computer, equipped with $2 \times$ Intel $^{\circledR}$ Xeon processors ( 8 cores), at $2.5 \mathrm{GHz}$, with $256 \mathrm{~GB}$ of RAM, running on Windows ${ }^{\circledR} 8$ Professional, 64 bits.

Several simulations were performed depending on the heating rate being tested (from 1 to $\left.13^{\circ} \mathrm{C} / \mathrm{min}\right)$.

\subsubsection{Microbial inactivation model}

The dynamic non log-linear model developed by Geeraerd et al. (2000) was selected in this study. The reduced model, without the tailing effect, consists of two coupled ordinary differential equations as follows:

$$
\frac{d N}{d t}=-k_{\max }\left(\frac{1}{1+C_{c}}\right) N
$$

where $N$ represents the microbial cell density (CFU/g). In equation $10, \frac{d N}{d t}$ is forced to zero once the limit of detection $(1 \mathrm{CFU} / \mathrm{g})$ is reached. $k_{\max }$ denotes the specific inactivation rate $\left(\mathrm{s}^{-}\right.$ ${ }^{1}$ ) and $C_{c}$ is related to the physiological state of cells (-). A single value for $C_{c}(0)$ can be used for all experiments, since the methodology of inoculation is standardized. Consequently, a similar initial physiological state is expected for cells

The temperature effect on kinetic parameters $\left(k_{\max }\right)$ was expressed using Bigelow's (1921) equation:

$$
k_{\max }(T)=\frac{\ln 10}{D_{\text {ref }}} \exp \left(\frac{\ln 10}{z}\left(T-T_{\text {ref }}\right)\right)
$$


where $D_{\text {ref }}$ denotes the decimal reduction time (s) at the reference temperature $T_{\text {ref }}$ and $z$-value the thermal resistance constant $\left({ }^{\circ} \mathrm{C}\right)$.

\subsubsection{Parameter estimation procedure}

The approach consists in estimating the model parameters of Equation 12 by minimizing the residual sum of squares (RSS):

$$
R S S=\sum_{i=1}^{n}\left(\log \frac{\frac{1}{v} \int N_{\text {simu }}\left(t_{i}\right) d v}{N_{0}}-\log \frac{\bar{N}_{\exp }\left(t_{i}\right)}{N_{0}}\right)^{2}
$$

where $t_{i}$ are the times at which the thermocouple located in the sample reached the expected the temperatures (respectively 50,52,54,56, 58,60,62 and $64{ }^{\circ} \mathrm{C}$ ), $n$ is the number of experimental data points, $N_{\text {simu }}$ is the volume-averaged value of the simulated cell density at $t_{i}$. $N_{\exp }$ is the volume-averaged value of the triplicate experimental cell density at $t_{i} . V$ is the volume of the sample and $N_{0}$ is the initial cell density.

To minimize the RSS, the Levenberg-Marquardt algorithm (lsqnonlin available in Matlab ${ }^{\circledR}$ 7.10) was used. This algorithm is based on the least-squares minimization technique and is an improvement of the Gauss-Newton algorithm. In addition, confidence intervals at 95\% were calculated for the estimated parameters using nlparci function available in Matlab ${ }^{\circledR} 7.10$.

\subsubsection{Methodology used for model comparison and selection}

Considering the model proposed by Geeraerd et al. (2000), it appears that parameters $C_{c}(0)$, $D_{r e f}$ and $z$-value can be estimated to fit the experimental data. Nevertheless, it is necessary to evaluate the relevance of the number of adjusted parameters. In this contribution, a non-linear least squares approach based on minimization of the RSS (residual sum of squares) is used. It evaluates the well-known Akaike Information Criterion (AIC) (Akaike, 1974), which provides a means for model selection. AIC is established as follows, on the assumption that the residues distribution is Gaussian:

$$
A I C=2 p-2 \ln (L L)
$$


Where $p$ is number of independently adjusted parameters within the model and $L L$ is the maximum likelihood. If the AIC criterion is used only with the aim of comparing models, the following simplified expression is used:

$$
A I C^{*}=2 p+\frac{R S S}{\sigma^{2}}
$$

When the residual sum of squares are almost equal for two different models, the minimum AIC estimation selects the model with the lowest number of parameters according to the "principle of parsimony" (Yamaoka, Nakagawa, \& Uno, 1978). In addition, a variance $\sigma^{2}$ was calculated for each heating rate from the experimental results obtained in triplicate.

\section{Results and discussion}

\subsection{Specific heat of ground beef}

The apparent specific heat $\left(C_{p}\right)$ of ground beef at $5 \%$ fat was determined from 20 to $65{ }^{\circ} \mathrm{C}$. As can be observed in Figure 4, the $C_{p}$ values were found to be quite constant on the temperature range. The average measured value $\left(C_{p}=3.69 \pm 0.01 \mathrm{~kJ} \mathrm{~kg}^{-1} \mathrm{~K}^{-1}\right)$ is close to the reported one in the literature for meat product (Zhang, Lyng, Brunton, Morgan, \& McKenna, 2004). The $C_{p}$ average value was integrated directly into the heat transfer model.

\subsection{Heat transfer and CFD model validation}

To validate the modelling approach, the experimental temperatures measured as a function of time in both the water and the sample were compared to the one simulated from the CFD-heat transfer model. Figure 5 illustrates the case for a heat treatment at $10^{\circ} \mathrm{C} / \mathrm{min}$. The standard deviation of the experimental data was about $\pm 0.3^{\circ} \mathrm{C}$, corresponding to the measuring accuracy of the thermocouple used. Figure 5 depicts the linear setting temperature. The agreement between experimental and model temperatures of the water and the sample is noticeable. Non-negligible thermal delays (about $26 \mathrm{~s}$ and $57 \mathrm{~s}$ ) can be observed respectively between the water and the sample and the set temperature and the sample, justifying the interest of such an approach when heating rates are applied.

The CFD modelling enabled prediction of the velocity fields due to the natural convection problem within a static enclosure. The Navier-Stokes equation was solved by considering a laminar flow. The norm of the velocity field, for example at $10{ }^{\circ} \mathrm{C} / \mathrm{min}$, is depicted in Figure 6 
for different processing times. Fluid motion occurs (illustrated by black arrows in Figure 6), because of the temperature dependent thermophysical properties of water. Recirculation of the heating fluid leads to velocity gradients, with a maximum value of $2.5 \mathrm{~mm} / \mathrm{s}$ around the sample (norm of the velocity field). The Reynold number was calculated considering this maximum fluid velocity of $10{ }^{\circ} \mathrm{C} / \mathrm{min}$ with a value of 9.4 . This result clearly demonstrates a natural convection of water within a confined space, in which the flow regime is laminar.

Once the CFD approach is validated, the model illustrates the temperature gradients when heating rates are applied. Figure 7 illustrates the temperatures at the final time of simulation for the six different heating rates considered. Simulation was stopped when the simulated temperature of the corresponding point to the thermocouple position reached $64{ }^{\circ} \mathrm{C}$.

For all treatments the hottest zone was located at the surface of the sample, except for the upper central part, due to contact with ambient air (cooling). The coldest zone was along the central axis of the product. The temperature gap between the hottest and coldest zones increased with the applied heating rates, so $4.3,6.2,8.1,9.8,12.4$, and $15.8{ }^{\circ} \mathrm{C}$ for $1,3,5,7$, 10 and $13{ }^{\circ} \mathrm{C} / \mathrm{min}$, respectively.

To confirm the effect of temperature heterogeneities on the volumetric microbial inactivation, equations 10,11 and 12 were used. The simulation of the 3D local temperature distribution in the meat sample (CFD and heat transfer model solved by COMSOL $^{\circledR}$ and transposed to MATLAB ${ }^{\circledR}$ ) was performed to quantify the 3D local microbial inactivation. For example, under a thermal treatment at $10{ }^{\circ} \mathrm{C} / \mathrm{min}$, the numerical result illustrated a thermal cartography with hot and cold points. These temperature heterogeneities lead to heterogeneous local microbial inactivation represented by the hatched area in Figure 8.

In Figure 8, a total inactivation can be seen for the hottest point after 5.8 minutes. For the coldest point, the maximum inactivation achieved was of $2 \log _{10}$, at the end of treatment. However, it is not possible to experimentally validate these local microbial inactivation data, at every geometrical point of the domain. Consequently, the use of a mathematical model to describe the local microbial inactivation during a pasteurization process remains a relevant tool. More, it confirms the importance of considering the volumetric distribution of temperature in the meat product to accurately predict microbial inactivation. 


\subsection{Estimation of kinetic parameters of inactivation}

Various results can be found in the literature concerning evaluation of kinetic parameters ( $D_{\text {ref, }}, T_{\text {ref }}$ and $z$-value) under isothermal conditions. In a study of heat resistance of Escherichia coli 0157:H7 inoculated into 7\% fat ground beef, Ahmed et al. (1995) obtained a

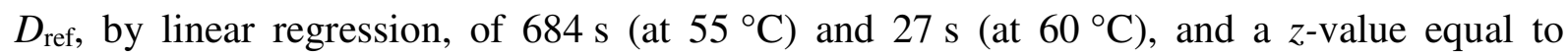
$4.78{ }^{\circ} \mathrm{C}$. In the same strain, but in ground beef with $4.8 \%$ fat, Smith et al. (2001) calculated by first-order kinetics a $D_{\text {ref }}$ equal to $73 \mathrm{~s} \mathrm{(at} 58{ }^{\circ} \mathrm{C}$ ) and $19 \mathrm{~s}$ (at $61^{\circ} \mathrm{C}$ ), for a $z$-value of $3.79^{\circ} \mathrm{C}$. These variations might be attributed to differences in the strains of $E$. coli used, the fat content of meat, along with differences in recovery methods and sample size (Smith et al., 2001; Stringer, George, \& Peck, 2000). In both studies, the values of $D_{\text {ref }}$ differ greatly whereas $z$ value remains in the same order of magnitude.

In this study, ground beef with 5\% fat was used and the heating rates described above were applied. Despite these dynamical conditions, in a first approach, the parameters $D_{\text {ref }}=73 \mathrm{~s}, z$ value $=3.79{ }^{\circ} \mathrm{C}$ and $T_{\text {ref }}=58{ }^{\circ} \mathrm{C}$ obtained by Smith et al. (2001) in isothermal conditions and $C_{C}(0)=0.23$, as reported in Hamoud-Agha et al. (2013), were used in the Geeraerd et al. (2000) model. Results are illustrated in Figure 9. Black circles illustrate the experimental data in triplicate, whereas the predictions obtained using the aforementioned parameters are represented by broken blue lines. Note that the model underestimates the experimental inactivations, but this underestimation has the same order of magnitude whatever the heating rate.

A second approach consisted in estimating the model parameters from the dynamic experiments. First, the triplet parameters $C_{c}(0), D_{r e f}$ and $z$-value were estimated. Poschet et al., (2005) showed that the uncertainties on $D_{\text {ref }}$ and $z$-value are minimal when $T_{\text {ref }}$ is equal to the middle of the lethal experimental temperature range. As $D_{\text {ref }}$ is closely linked to $T_{\text {ref, }}$ this value was fixed at $58{ }^{\circ} \mathrm{C}$, as defined in Smith et al. (2001). The $\mathrm{C}_{\mathrm{c}}(0)$ value was estimated with a lower bound equal to zero. In table $3, \mathrm{C}_{\mathrm{c}}(0)$ is not significantly different from zero for all heating rates. Consequently, equation (11) can be removed and the Geeraerd et al. (2000) model becomes a classical first order inactivation model.

With the Bigelow model, the $D_{\text {ref }}$ and $z$-values were estimated (Table 4). It should be noted that these $\mathrm{AIC}^{*}$ values are lower than the $\mathrm{AIC}^{*}$ values obtained in previous estimate procedure with three parameters (Table 3). The confidence intervals for $D_{\text {ref }}$ increase for extreme heating rates $\left(10\right.$ and $\left.13{ }^{\circ} \mathrm{C} / \mathrm{min}\right)$, certainly due to the large thermal heterogeneities. Another 
explanation is based on Van Derlinden, Balsa-Canto, \& Van Impe, (2012), where the authors discussed the link between parameter identifiability and the shape of the temperature profile. The results of $z$-value indicated in Table 4 are consistent with those presented by Smith et al. (2001), for a similar product at $58^{\circ} \mathrm{C}\left(z\right.$-value $\left.=3.79{ }^{\circ} \mathrm{C}\right)$. Indeed, this value $\left(3.79{ }^{\circ} \mathrm{C}\right)$ is almost included in the confidence intervals and will thus be considered hereafter.

With the estimation limited to $D_{r e f}$, the confidence intervals are widely reduced, even if they remain significant for heating rates of 10 and $13{ }^{\circ} \mathrm{C} / \mathrm{min}(12.52 \mathrm{~s}$ and $8.75 \mathrm{~s})$. These results are summarized in Table 5. Compared to Table 4, quite similar or lower values of the AIC* were obtained. It appears that adjusting $D_{\text {ref }}$ is sufficient to fit the experiments without degrading the AIC* values. Moreover, it also reduces the parameter uncertainties as verified with 95\% confidence intervals.

Thereby, for one estimated parameter, the $D_{\text {ref }}$ values remain in the same order of magnitude. Consequently, the average of the previously estimated $D_{\text {ref }}$ values (Table 5) of $47 \mathrm{~s}$ was used. The predicted inactivation curves obtained in this case are presented in black continuous line in Figure 9. They are very close to inactivation results obtained with each estimated $D_{\text {ref }}$ (red dotted line is superimposed on black continuous line in figure 9). Hence, for $D_{\text {ref }}$ values ranging from 40 to $50 \mathrm{~s}$, considering a unique value of $47 \mathrm{~s}$ does not significantly affect the inactivation predictions.

Finally, results reveal that the $k_{\max }$ expression with temperature dependence proposed by Bigelow is sufficient to fit experimental data obtained in dynamic conditions with large temperature heterogeneities $\left(>15{ }^{\circ} \mathrm{C}\right.$ for $\left.13{ }^{\circ} \mathrm{C} / \mathrm{min}\right)$, provided that these heterogeneities are considered in the prediction model. Constant values for $T_{\text {ref }}, z$ and $D_{\text {ref }}$ can be considered for all heating rates in the range 1 to $13{ }^{\circ} \mathrm{C} / \mathrm{min}$. Additionally, $T_{\text {ref }}$ and z-values of literature (Smith et al., 2001) were used with only a fitting of $D_{\text {ref. }}$.

\section{Conclusion}

The contribution of this work lies in the integration of experimental and numerical approaches dedicated to the real-food pasteurization process including both thermal and inactivation kinetics with high heating rates.

The originality of this paper lies $(i)$ in the integration of three-dimensional heat transfer conditions in parameter estimations applied to the inactivation model and (ii) in the application of extreme heating rates to challenge the validity of the Geeraerd modelling 
approach developed for isothermal conditions. The heat transfer model was validated during blank tests, and the volume-average of logarithmic inactivation was considered to be comparable with experimental data. In addition, the experiments were carried out on real ground beef, and not in capillary tubes, as usually proposed. The inactivation model was coupled with heat transfer to design a 3D simulator to predict the spatial distribution of logarithmic inactivation of $E$. coli in a meat sample.

Such a 3D simulator illustrates how the temperature gradients can provoke large inactivation heterogeneities, and thus the necessity to consider them in realistic pasteurization conditions. The satisfactory agreement between model and experiments allows coupling of the modelling approach with process control procedures, allowing energy supply to reach the expected microbial inactivation while limiting temperature heterogeneities. Such an objective could be reached for example by using combined energy sources with volumetric heating to avoid overtreatment at the surface of the food product (microwaves, ohmic heating).

\section{Acknowledgments}

The authors are grateful to the National Council for Scientific and Technological Development (CNPq, Brazil) for C. D. Albuquerque's PhD scholarship and financial support (process number 232767/2014-9).

\section{References}

Ahmed, N. M., Conner, D. E., \& Huffman, D. L. (1995). Heat-resistance of Escherichia Coli O157:H7 in meat and poultry as affected by product composition. Journal of Food Science, 60(3), 606-610.

Akaike, H. (1974). A New Look at the Statistical Model Identification. IEEE Transactions on Automatic Control, 19(6), 716-723.

Bhuvaneswari, E., \& Anandharamakrishnan, C. (2014). Heat transfer analysis of pasteurization of bottled beer in a tunnel pasteurizer using computational fluid dynamics. Innovative Food Science and Emerging Technologies, 23, 156-163.

Bigelow, W. D. (1921). The logarithmic nature of thermal death time curves. The Journal of Infectious Diseases, 29(5), 528-536.

Boillereaux, L., Curet, S., Hamoud-Agha, M., \& Simonin, H. (2013). Model-based settings of a conveyorized microwave oven for minced beef simultaneous cooking and pasteurization. In Computer Applications in Biotechnology (CAB 2013). Mumbai, India. 
Bott, R. (2014). Modelling microorganisms in food. (S. Brul, Suzanne van Gerwen, \& M. Zwietering, Eds.), Woodhead Publishing Limited, Abington Hall, Abington. Cambridge.

Chen, G. (2013). Estimating microbial survival parameters from dynamic survival data using Microsoft Excel. International Journal of Food Science and Technology, 48(9), 18411846.

Chung, H. J., Wang, S., \& Tang, J. (2007). Influence of heat transfer with tube methods on measured thermal inactivation parameters for Escherichia coli. Journal of Food Protection, 70(4), 851-859.

Churchill, S. W., \& Chu, H. H. S. (1975). Correlating equations for laminar and turbulent free convection from a vertical plate. International Journal of Heat and Mass Transfer, $18(11), 1323-1329$.

Cordioli, M., Rinaldi, M., Copelli, G., Casoli, P., \& Barbanti, D. (2014). Computational fluid dynamics (CFD) modelling and experimental validation of thermal processing of canned fruit salad in glass jar. Journal of Food Engineering, 150, 62-69.

Denys, S., Pieters, J. G., \& Dewettinck, K. (2003). Combined CFD and experimental approach for determination of the surface heat transfer of the surface heat transfer coefficient during thermal processing of eggs. Journal of Food Science, 68(3).

Dimou, A., \& Yanniotis, S. (2011). 3D numerical simulation of asparagus sterilization in a still can using computational fluid dynamics. Journal of Food Engineering, 104(3), 394403.

Franklin R. Cockerill, III, MD Matthew A. Wikler, MD, MBA, FIDSA Jeff Alder, PhD Michael N. Dudley, PharmD, FIDSA George M. Eliopoulos, MD Mary Jane Ferraro, PhD, MPH Dwight J. Hardy, PhD David W. Hecht, M., \& Janet A. Hindler, MCLS, MT(ASCP) Jean B. Patel, PhD, D(ABMM) Mair Powell, MD, FRCP, FRCPath Jana M. Swenson, MMSc Richard B. Thomson, Jr., PhD Maria M. Traczewski, BS, MT(ASCP) John D. Turnidge, MD Melvin P. Weinstein, MD Barbara L. Zimmer, P. (2012). Methods for Dilution Antimicrobial Susceptibility Tests for Bacteria That Grow Aerobically; Approved Standard - Ninth Edition. In Clinical and Laboratory Standards Institute Advancing (Vol. 32, p. 88).

Garre, A., Huertas, J. P., González-Tejedor, G. A., Fernández, P. S., Egea, J. A., Palop, A., \& Esnoz, A. (2018). Mathematical quantification of the induced stress resistance of microbial populations during non-isothermal stresses. International Journal of Food Microbiology, 266(September 2017), 133-141.

Geeraerd, A. H., Herremans, C. H., \& Van Impe, J. F. (2000). Structural model requirements 
to describe microbial inactivation during a mild heat treatment. International Journal of Food Microbiology, 59(3), 185-209.

Green, D. W., \& Perry, R. H. (2007). Perry's Chemical Engineering Handbook (Eighth). The McGraw-Hill Companies, Inc.

Hamoud-Agha, M. M., Curet, S., Simonin, H., \& Boillereaux, L. (2013). Microwave inactivation of Escherichia coli K12 CIP 54.117 in a gel medium: experimental and numerical study. Journal of Food Engineering, 116(2), 315-323.

Hassani, M., Cebrián, G., Mañas, P., Condón, S., \& Pagán, R. (2006). Induced thermotolerance under nonisothermal treatments of a heat sensitive and a resistant strain of Staphylococcus aureus in media of different pH. Letters in Applied Microbiology, 43(6), 619-624.

ISO 16649-1:2001.Microbiology of food and animal feeding stuffs - Horizontal method for the enumeration of beta-glucuronidase-positive Escherichia coli - Part 1: Colony-count technique at 44 degrees $\mathrm{C}$ using membranes and 5-bromo-4-chloro-3-indolyl. (2001).

Juneja, V. K., \& Marks, H. M. (2003). Characterizing asymptotic D -values for Salmonella spp . subjected to different heating rates in sous-vide cooked beef, 4, 395-402.

Marcotte, M., Chen, C. R., Grabowski, S., Ramaswamy, H. S., \& Piette, J. P. G. (2008). Modelling of cooking-cooling processes for meat and poultry products. International Journal of Food Science and Technology, 43(4), 673-684.

Marquardt, D. W. (1963). An algorithm for least-squares estimation of nonlinear parameters. Journal of the Society for Industrial and Applied Mathematics.

Pan, Z., \& Paul Singh, R. (2001). Physical and thermal properties of ground beef during cooking. LWT - Food Science and Technology, 34(7), 437-444.

Poschet, F., Geeraerd, A. H., Loey, A. M. Van, Hendrickx, M. E., \& Impe, J. F. Van. (2005). Assessing the optimal experiment setup for first order kinetic studies by Monte Carlo analysis, 16, 873-882.

Smith, S. E., Maurer, J. L., Orta-Ramirez, A., Ryser, E. T., \& Smith, D. M. (2001). Thermal inactivation of Salmonella spp., Salmonella typhimurium DT104, and Escherichia coli O157 : H7 in ground beef. Food Microbiology and Safety Thermal, 66(8), 1164-1168.

Stratakos, A. C., \& Koidis, A. (2015). Suitability, efficiency and microbiological safety of novel physical technologies for the processing of ready-to-eat meals, meats and pumpable products. International Journal of Food Science and Technology, 50(6), 12831302.

Stringer, S. C., George, S. M., \& Peck, M. W. (2000). Thermal inactivation of Escherichia 
coli 0157 : H7. Joumal of Applied Microbiology Symposium Supplement, 88(Coia 1998), 79S-89S.

Tsai, S. J., Unklesbay, N., Unklesbay, K., \& Clarke, A. (1998). Thermal properties of restructured beef products at different isothermal temperatures. Journal of Food Science, 63(3), 481-484.

Valdramidis, V. P., Belaubre, N., Zuniga, R., Foster, A. M., Havet, M., Geeraerd, A. H., ... Kondjoyan, A. (2005). Development of predictive modelling approaches for surface temperature and associated microbiological inactivation during hot dry air decontamination. International Journal of Food Microbiology, 100(1-3), 261-274.

Valdramidis, V. P., Geeraerd, A. H., Bernaerts, K., \& Van Impe, J. F. (2006). Microbial dynamics versus mathematical model dynamics: The case of microbial heat resistance induction. Innovative Food Science and Emerging Technologies, 7(1-2), 80-87.

Valdramidis, V. P., Geeraerd, A. H., \& Impe, J. F. Van. (2007). Stress-adaptive responses by heat under the microscope of predictive microbiology. Journal of Applied Microbiology, $1,1922-1930$.

Van Derlinden, E., Balsa-Canto, E., \& Van Impe, J. F. M. (2012). (Optimal) experiment design for microbial inactivation. In Progress on quantitative approaches of thermal food processing. In Vasilis P. Valdramidis \& Jan F. M. Van Impe (Eds.), Progress on Quantitative Approaches of Thermal Food Processing (pp. 67-98). Nova Publishers.

Vilas, C., Arias-Méndez, A., García, M. R., Alonso, A. A., \& Balsa-Canto, E. (2018). Toward predictive food process models: A protocol for parameter estimation. Critical Reviews in Food Science and Nutrition, 58(3), 436-449.

Yamaoka, K., Nakagawa, T., \& Uno, T. (1978). Application of Akaike's information criterion (AIC) in the evaluation of linear pharmacokinetic equations. Journal of Pharmacokinetics and Biopharmaceutics, 6(2), 165-175.

Zhang, L., Lyng, J. G., Brunton, N., Morgan, D., \& McKenna, B. (2004). Dielectric and thermophysical properties of meat batters over a temperature range of $5-85^{\circ} \mathrm{C}$. Meat Science, 68(2), 173-184. 


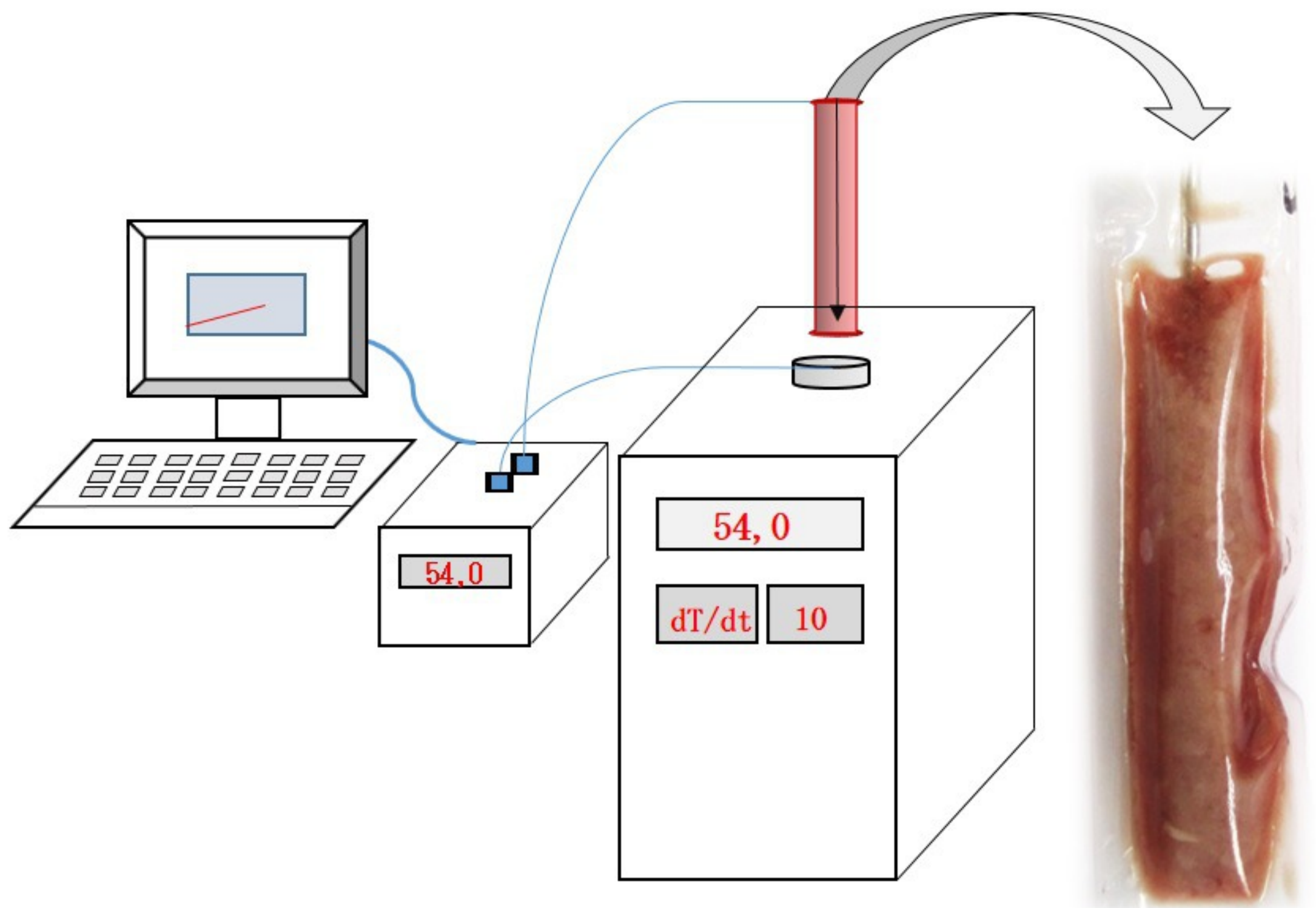




\section{$T_{\infty}, P_{a t m}$}

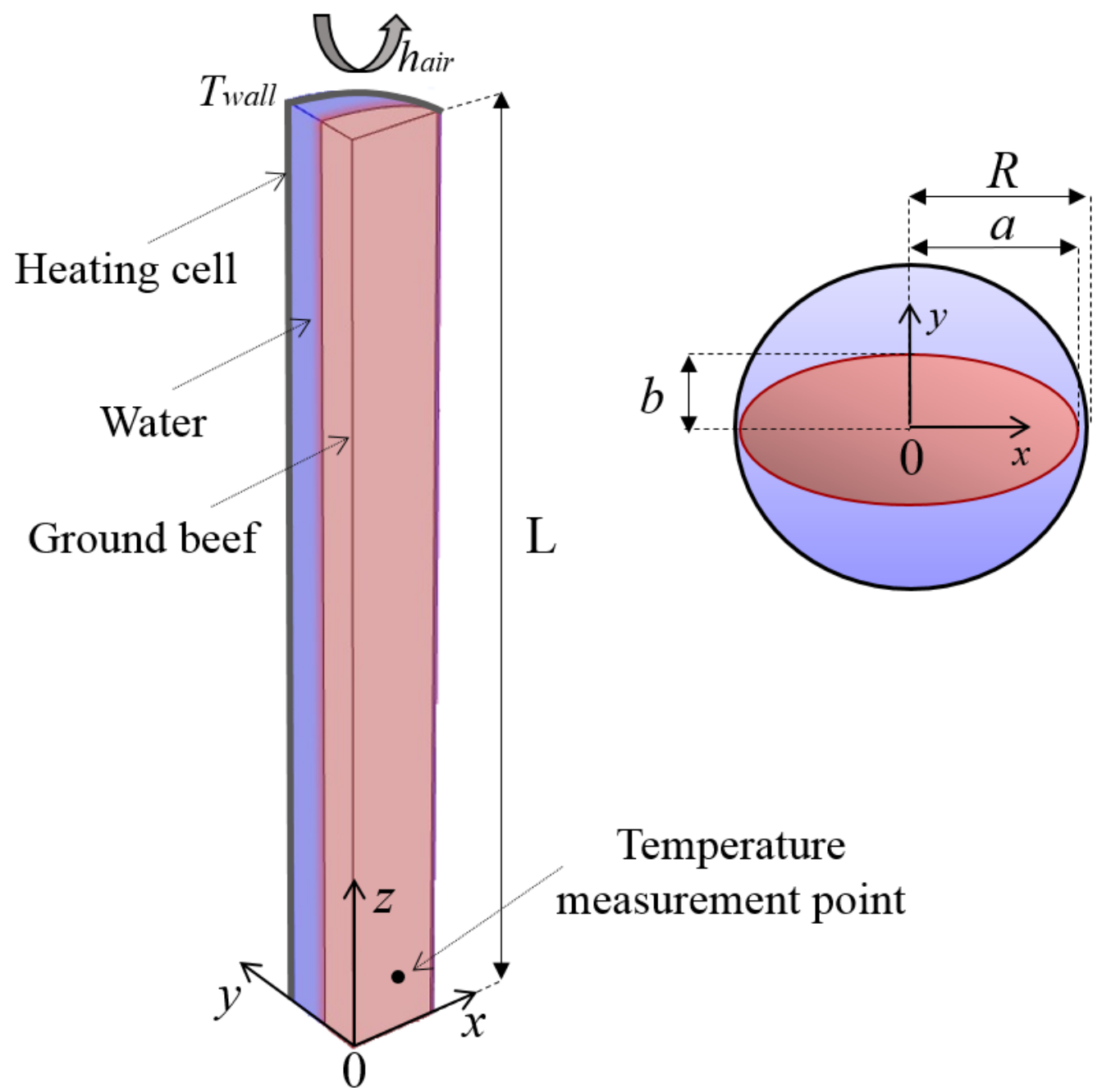




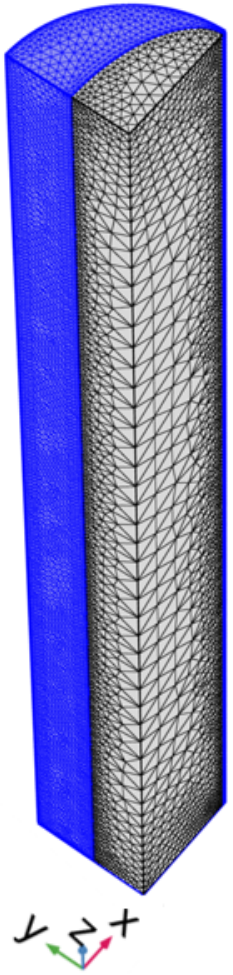




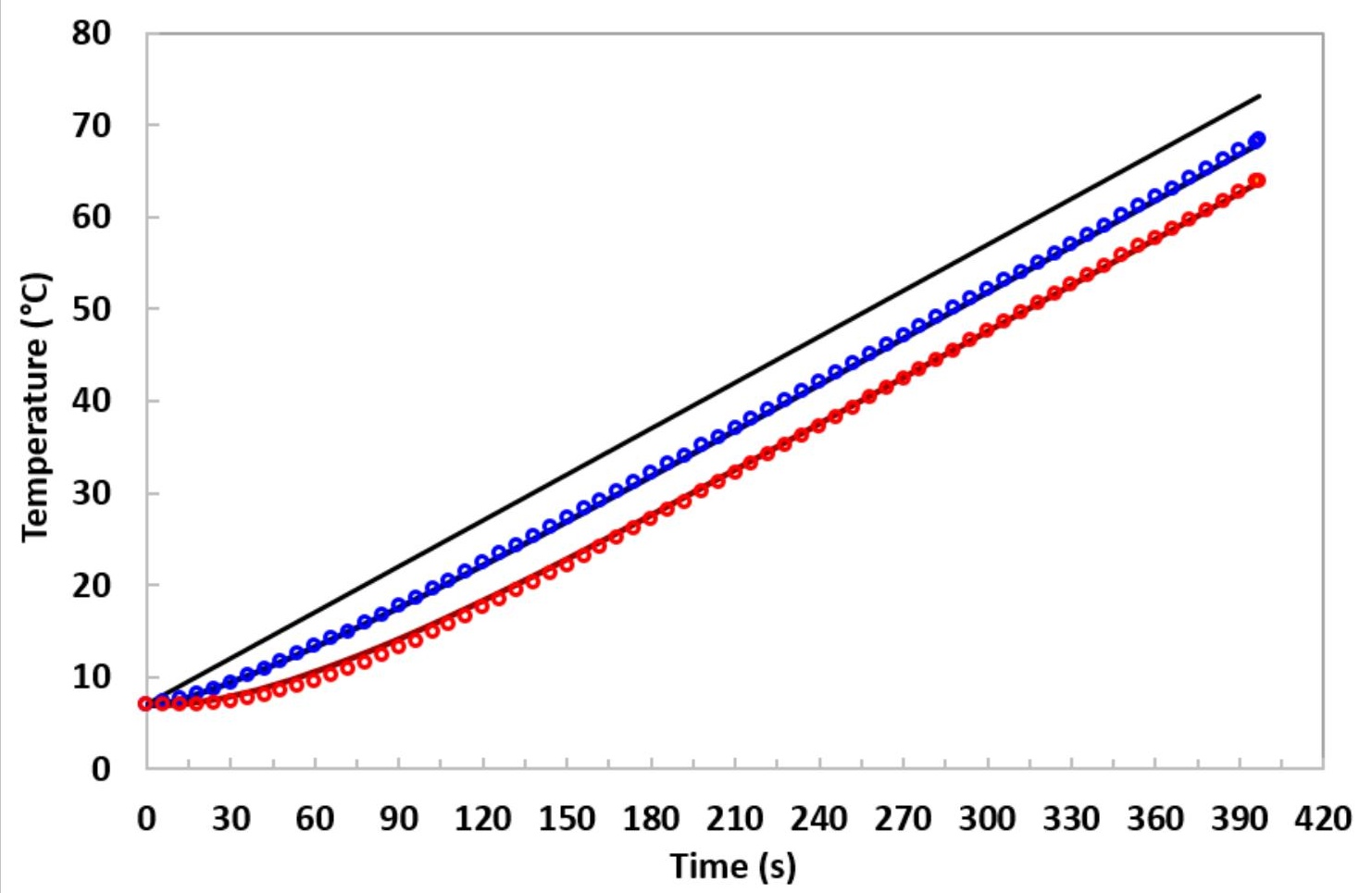




\section{$\mathrm{mm} / \mathrm{s}$}

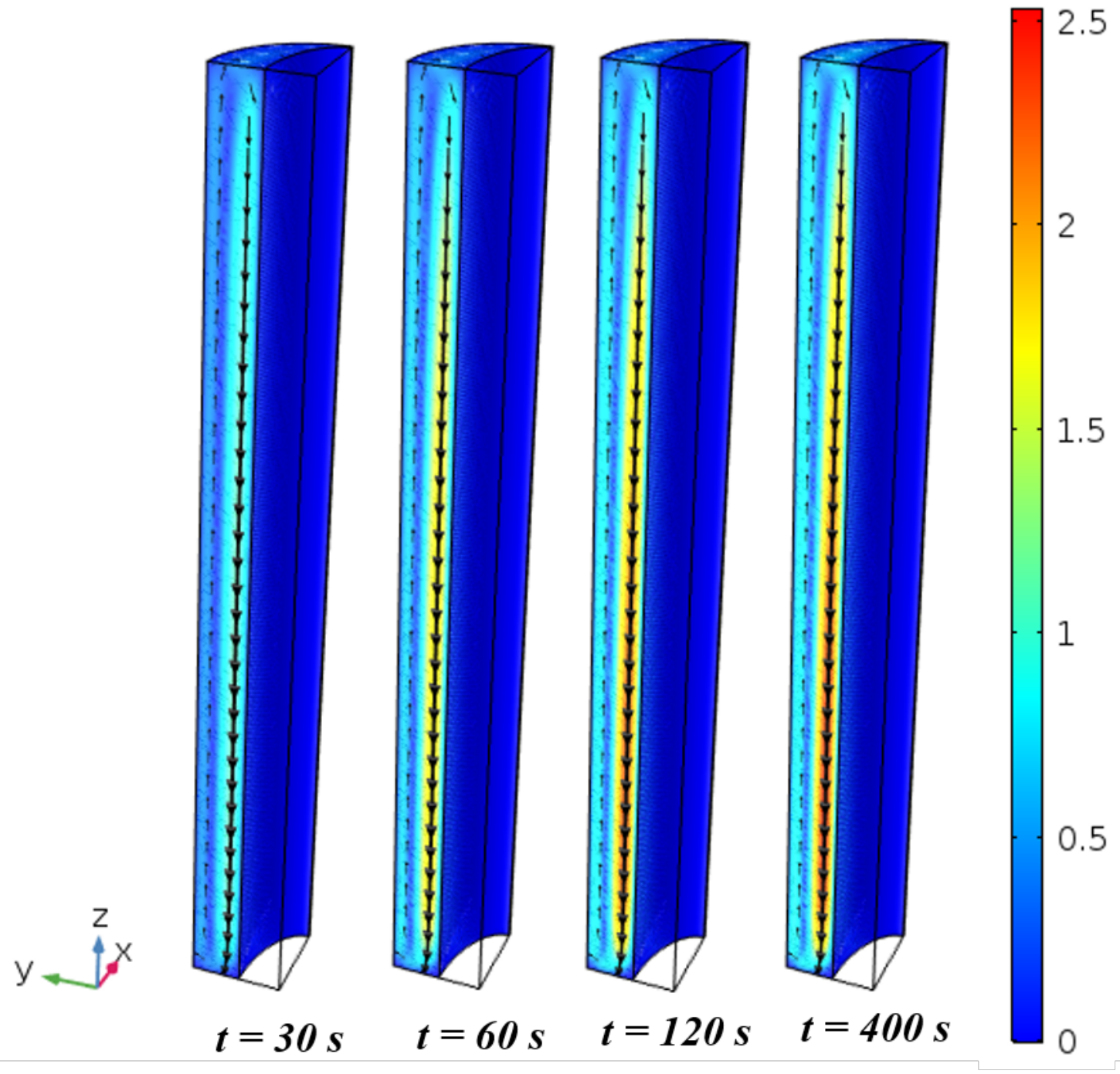




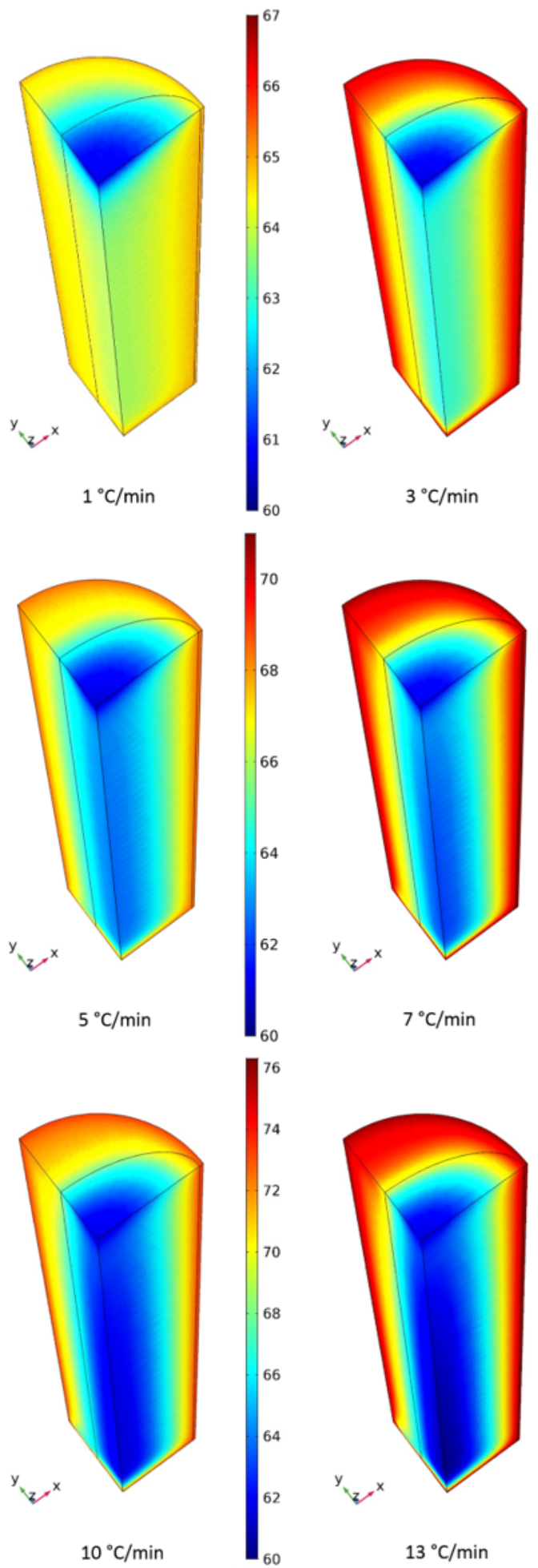




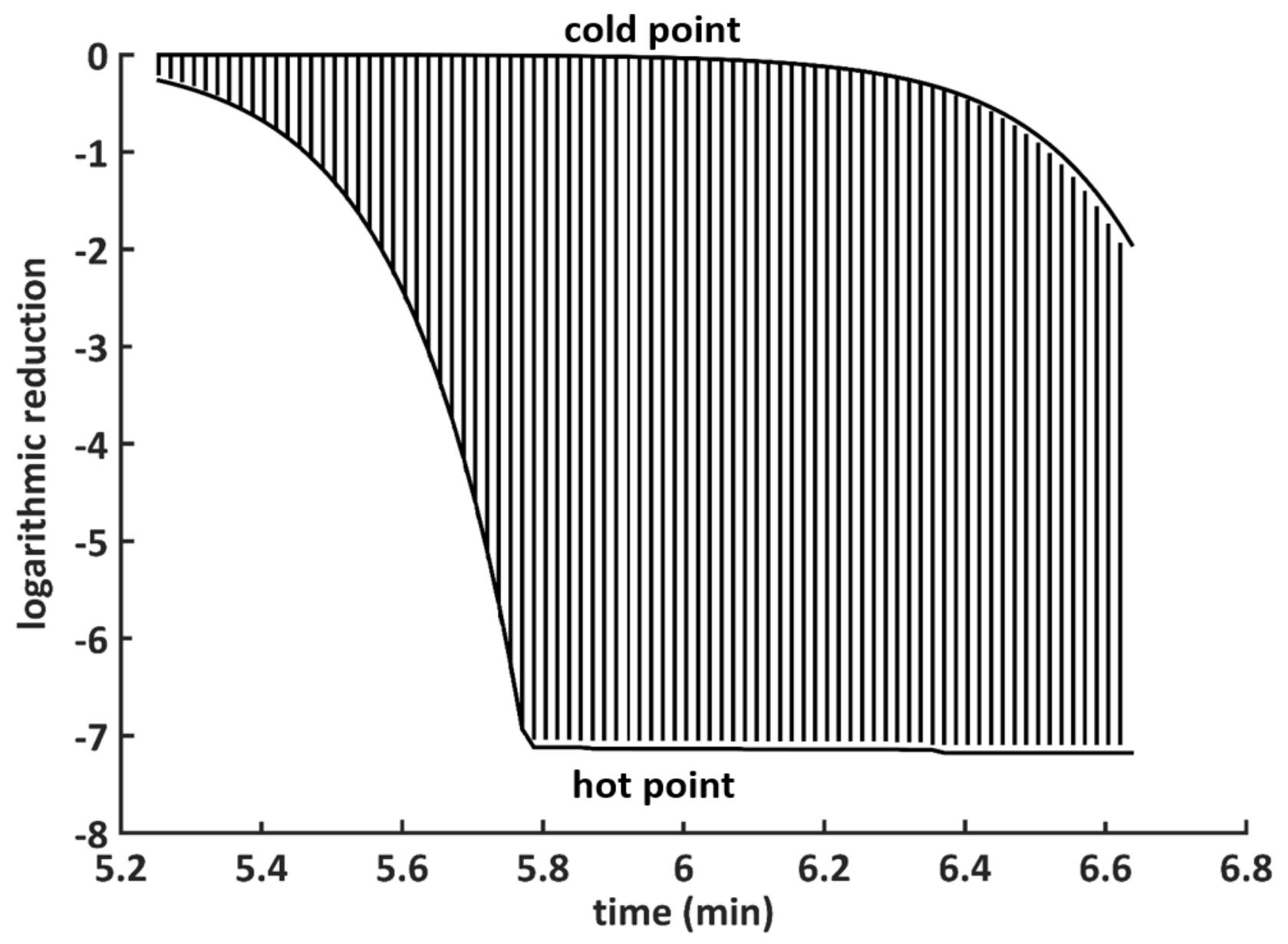



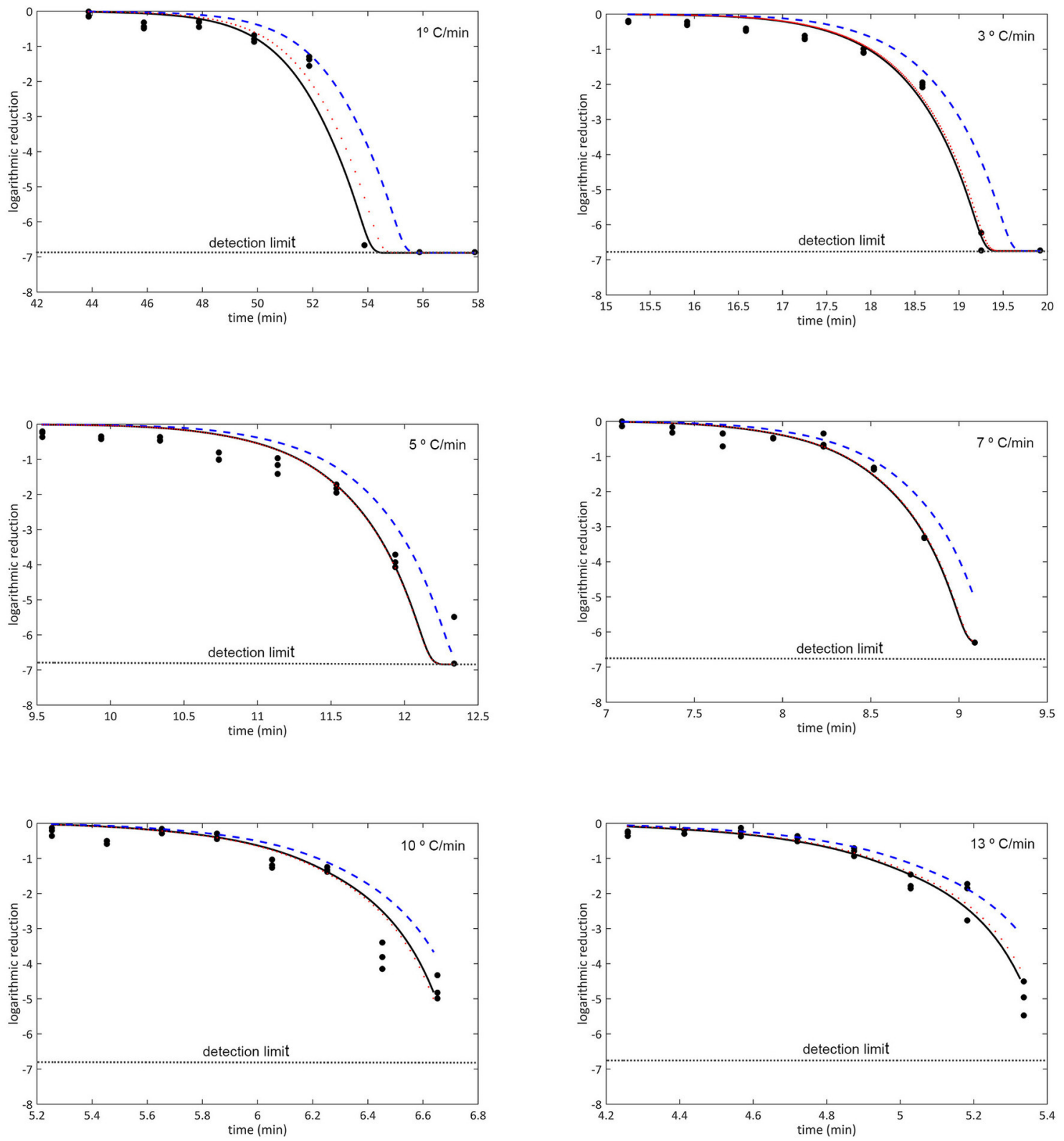
Table 1. Thermophysical properties of ground beef.

\begin{tabular}{llll}
\hline Properties & Value & Unit & Source \\
\hline Apparent specific heat $\left(\mathrm{C}_{\mathrm{p}}\right)$ & $3.69 \pm 0.01$ & $\mathrm{~kJ} \mathrm{~kg}^{-1} \mathrm{~K}^{-1}$ & Experimental \\
Thermal conductivity $(\lambda)$ & 0.35 & $\mathrm{~W} \mathrm{~m}^{-1}{ }^{\circ} \mathrm{C}^{-1}$ & Pan and Singh (2001). \\
Density $(\rho)$ & 1006 & $\mathrm{~kg} / \mathrm{m}^{3}$ & Pan and Singh (2001).
\end{tabular}

Table 2. Thermophysical properties of water as a function of temperature (Kelvin).

\begin{tabular}{|c|c|}
\hline Functions of the properties* & Unit \\
\hline$C_{p}=12010.15-80.41 \times T+0.31 \times T^{2}-5.38 \times 10^{-4} \times T^{3}+3.62 \times 10^{-7} \times T^{4}$ & $\mathrm{~J} \mathrm{~kg}^{-1} \mathrm{~K}^{-1}$ \\
\hline$\lambda=-0.87+8.95 \times 10^{-3} \times T-1.58 \times 10^{-5} \times T^{2}+7.97 \times 10^{-9} \times T^{3}$ & $\mathrm{~W} \mathrm{~m}^{-1}{ }^{\circ} \mathrm{K}^{-1}$ \\
\hline$\rho=838.47+1.40 \times T-3.01 \times 10^{-3} \times T^{2}+3.72 \times 10^{-7} \times T^{3}$ & $\mathrm{~kg} / \mathrm{m}^{3}$ \\
\hline
\end{tabular}

*Green \& Perry, 2007

Table 3. Estimated values of $D_{\text {ref, }} z$-value and $C_{c}(0)$, for $T_{\text {ref }}=58^{\circ} \mathrm{C}$. Standard deviation of experimental data $\left(\sigma^{2}\right)$, 95\% confidence intervals $(\mathrm{CI})$ and simplified Akaike Information Criterion $\left(\mathrm{AIC}^{*}\right)$.

\begin{tabular}{ccccccccc}
\hline $\begin{array}{c}\text { Heating rate } \\
\left({ }^{\circ} \mathrm{C} / \mathrm{min}\right)\end{array}$ & $\sigma^{2}$ & $D_{\text {ref }}(\mathrm{s})$ & $\mathrm{CI} D_{\text {ref }}$ & $\begin{array}{c}z \text {-value } \\
\left({ }^{\circ} \mathrm{C}\right)\end{array}$ & $\mathrm{CI} z$-value & $C_{c}(0)$ & $\begin{array}{c}\text { CI } \\
C_{c}(0)\end{array}$ & AIC $^{*}$ \\
\hline 1 & 0.24 & 33.1 & 3.8 & 1.96 & 1.41 & 0 & 0.30 & 11.8 \\
3 & 0.20 & 48.9 & 6.8 & 3.81 & 0.63 & 0 & 0.21 & 12.2 \\
5 & 0.23 & 41.7 & 5.3 & 7.32 & 1.53 & 0.11 & 0.15 & 10.2 \\
7 & 0.34 & 45.7 & 8.1 & 3.59 & 0.61 & 0.21 & 0.18 & 9.3 \\
10 & 0.50 & 56.2 & 22.4 & 6.19 & 2.3 & 0.08 & 0.17 & 11 \\
13 & 0.63 & 74.7 & 33.1 & 2.99 & 0.69 & 0.04 & 0.15 & 9.2 \\
\hline
\end{tabular}


Table 4. Estimated values of $D_{\text {ref }}$ and $z$-value $\left(T_{\text {ref }}=58^{\circ} \mathrm{C}\right)$. Standard deviation of experimental data $\left(\sigma^{2}\right), 95 \%$ confidence intervals (CI) and simplified Akaike Information Criterion (AIC ${ }^{*}$ ).

\begin{tabular}{ccccccc}
\hline $\begin{array}{c}\text { Heating rate } \\
\left({ }^{\circ} \mathrm{C} / \mathrm{min}\right)\end{array}$ & $\sigma^{2}$ & $D_{\text {ref }}(\mathrm{s})$ & $\mathrm{CI} D_{\text {ref }}$ & $\begin{array}{c}z \text {-value } \\
\left({ }^{\circ} \mathrm{C}\right)\end{array}$ & $\mathrm{CI} z$-value & AIC $^{*}$ \\
\hline 1 & 0.24 & 33.1 & 3.8 & 1.96 & 1.41 & 8.8 \\
3 & 0.20 & 48.9 & 6.8 & 3.81 & 0.63 & 9.2 \\
5 & 0.23 & 40.8 & 5.1 & 6.70 & 1.41 & 7.2 \\
7 & 0.34 & 31.4 & 12.4 & 4.80 & 0.81 & 7.2 \\
10 & 0.50 & 62.1 & 23.2 & 5.98 & 2.65 & 8.2 \\
13 & 0.63 & 73.1 & 32.6 & 3.02 & 0.71 & 6.6 \\
\hline
\end{tabular}

Table 5. Estimated values of $D_{\text {ref }}\left(z=3.79\right.$ and $\left.T_{\text {ref }}=58^{\circ} \mathrm{C}\right)$. Standard deviation of experimental data $\left(\sigma^{2}\right), 95 \%$ confidence intervals (CI) and simplified Akaike Information Criterion $\left(\mathrm{AIC}^{*}\right)$.

\begin{tabular}{ccccc}
\hline $\begin{array}{c}\text { Heating rate } \\
\left({ }^{\circ} \mathrm{C} / \mathrm{min}\right)\end{array}$ & $\sigma^{2}$ & $D_{\text {ref }}(\mathrm{s})$ & CI $D_{\text {ref }}$ & AIC $^{*}$ \\
\hline 1 & 0.24 & 40.1 & 0.03 & 9 \\
3 & 0.20 & 47.5 & 0.38 & 6.2 \\
5 & 0.23 & 50.0 & 0.59 & 8.2 \\
7 & 0.34 & 50.0 & 0.48 & 3.6 \\
10 & 0.50 & 50.1 & 12.52 & 6.8 \\
13 & 0.63 & 46.7 & 8.75 & 3.6 \\
\hline
\end{tabular}

